\title{
Does left heart disease cause most systemic sclerosis associated pulmonary hypertension?
}

\author{
Gerry Coghlan
}

Affiliations: Department of Cardiology, Royal Free Hospital, London, UK.

Correspondence: G. Coghlan, Dept of Cardiology, Royal Free Hospital, Pond Street, London, NW3 2QG, UK. E-mail: gerry.coghlananhs.net

0

@ERSpublications

In systemic sclerosis we should ask what, in this individual patient, is the driver for elevated pulmonary pressures? http://ow.ly/nwLNM

In this issue of the European Respiratory Journal, Fox et al. [1] present data that suggest most pulmonary hypertension $(\mathrm{PH})$ in systemic sclerosis is post-capillary and that many patients are receiving pulmonary vasodilator therapy inappropriately. Of 53 patients identified as having $\mathrm{PH}$, nearly half (24) had elevated wedge pressures, a further five had elevated left ventricular end-diastolic pressure and another six were "exposed" as having occult post-capillary abnormalities in response to a $500-\mathrm{mL}$ fluid challenge administered over 5-10 min. Thus, in total, 35 (67\%) out of $53 \mathrm{PH}$ patients did not have pulmonary arterial hypertension (PAH). The number of patients with elevated pulmonary artery occlusion pressures (PAOP) is high when compared with other studies $[2,3]$ and there is no "threshold" wedge pressure that differentiates normality from cardiac disease during fluid challenge $[4,5]$, but this misses the bigger point. Their work illustrates the flaws in the accepted diagnostic benchmark.

These issues may seem of relevance only to rheumatologists, but as the average age of patients with idiopathic PAH increases [6], requiring diagnosis of PAH in the presence of diastolic dysfunction, and as increased numbers of patients with diastolic heart failure and $\mathrm{PH}$ [7] are referred for consideration of pulmonary vasodilator therapy, the same issues must be addressed by all clinicians with an interest in PH.

A haemodynamic definition of PAH was agreed by consensus in 1973 [8] to obviate the need for high risk lung biopsies it was modified in 2009 in recognition of the high variability of measured pulmonary vascular resistance to a simple requirement of mean pulmonary arterial pressure (PAP) $\geqslant 25 \mathrm{mmHg}$, plus a PAOP and/ or left ventricular end-diastolic pressure (LVEDP) $\leqslant 15 \mathrm{mmHg}$, with a normal or reduced cardiac output [9].

This definition works well for classical cases, given that the average LVEDP in heart failure associated PH has been reported at $23 \mathrm{mmHg}$ for a mean PAP of $34 \mathrm{mmHg}$ [10], while in PAH, the PAOP is on average normal (mean of eight) for a mean PAP of $>50 \mathrm{mmHg}$ [6]. For borderline cases, common sense indicates that rare conditions (idiopathic PAH incidence less than four per million [11]) can be dismissed in favour of common conditions (heart failure or lung disease associated $\mathrm{PH}$ account for $80 \%$ of all $\mathrm{PH}$ ).

In systemic sclerosis, no such common sense algorithm exists, as group 1 and $2 \mathrm{PH}$ are both common. Cardiac magnetic resonance [12] and post mortem [13] studies show that the majority of systemic sclerosis patients have some cardiac involvement; thus, $\mathrm{PAH}$ in systemic sclerosis could become virtually impossible to diagnose if exclusion of any left heart abnormality is a prerequisite for diagnosis. The question we should be asking is what, in this individual patient, is the driver for elevated pulmonary pressures?

Received: Feb 102013 | Accepted: Feb 122013

Conflict of interest: Disclosures can be found alongside the online version of this article at www.erj.ersjournals.com

Copyright @ERS 2013 
Mechanistically, post-capillary PH originates from elevated left atrial pressures. The PAOP is generally slightly higher than the mean left atrial pressure [14]. PAOP and LVEDP are not identical and discrepancies occur [15]. A compliant left atrium can protect the pulmonary vasculature from elevated LVEDP, while a stiff left atrium can result in post capillary PH in the setting of a normal LVEDP [16].

Poor practice may also explain many of the discrepancies reported. In many centres, mean pressure rather than end expiratory pressure is reported. Currently, most centres report post a-wave LVEDP, which correlates with end diastolic left atrial pressure and is higher than the mean left atrial pressure [17]. In wedge position confirmation, using contrast and/or saturations are rarely mentioned, and such measures may be reassuring despite over-wedging.

A further issue is that filling pressures vary over time, yet we work with single measures as a gold standard. In the Registry to Evaluate Early and Long-term Pulmonary Arterial Hypertension Disease Management (REVEAL) database, $10 \%$ of patients with an initial PAOP $\leqslant 12 \mathrm{mmHg}$ had a follow-up PAOP $\geqslant 16 \mathrm{mmHg}$, while $50 \%$ of patients with an initial PAOP $\geqslant 16 \mathrm{mmHg}$ had a follow-up PAOP $\leqslant 12 \mathrm{mmHg}$ [18]. Diuretics may have played some role in the latter observation but we do not have any definition of optimal fluid status in patients at the time of catheterisation.

NAEIJE et al. [19] have proposed using the diastolic-wedge gradient as a more reliable method of distinguishing PAH from PH. This is based on evidence that as PAOP increases in experimental situations, diastolic PAP and PAOP remain nearly identical [17]. Two studies provide indirect support for this concept. TATEBE et al. [20] studied 676 patients with symptomatic heart failure of various causes; of these, 100 had "passive PH" (PAOP $21 \mathrm{mmHg}$, diastolic PAP $20 \mathrm{mmHg}$ and mean PAP $30 \mathrm{mmHg}$ ) and 58 had reactive $\mathrm{PH}$, defined as a transpulmonary gradient (TPG) $>12 \mathrm{mmHg}$ or pulmonary vascular resistance $>2.5$ Wood units (PAOP $21 \mathrm{mmHg}$, diastolic PAP $24 \mathrm{mmHg}$ and mean PAP $35 \mathrm{mmHg}$ ). LeUNG et al. [10] studied patients with an LVEDP $>15 \mathrm{mmHg}$ and preserved left ventricular systolic function. 216 had no PH (mean PAP $20 \pm 4.1 \mathrm{mmHg}$; TPG $3.2 \pm 2.4 \mathrm{mmHg}$, suggesting a PAOP of $17.8 \mathrm{mmHg}$; LVEDP was $20 \pm 4.3 \mathrm{mmHg}$, thus higher than wedge in those without $\mathrm{PH}$; in this group the diastolic PAP was $12.6 \mathrm{mmHg}$, below either wedge or LVEDP) and 239 had PH (mean PAP $34.2 \pm 7.8 \mathrm{mmHg}$; TPG $12.4 \pm 8.1 \mathrm{mmHg}$, suggesting a PAOP of $21.8 \mathrm{mmHg}$; LVEDP was $22.7 \pm 5.8 \mathrm{mmHg}$; and the diastolic PAP was $22.2 \pm 6.8 \mathrm{mmHg}$ ) suggesting that diastolic-wedge gradient would continue to discriminate left heart from precapillary $\mathrm{PH}$. These data also suggest that where LVEDP exceeds the PAOP, this is due to preserved left atrial function protecting the pulmonary vascular tree from the impact of raised left-sided filling pressures.

We have only begun to get to grips with the complexities of diagnosing pulmonary vascular disease in the presence of left heart abnormalities. Further studies to elucidate the role of the left atrium, to understand the impact of acute fluid loading and the variability of haemodynamics over time are required.

\section{References}

1 Fox BD, Shimony A, Langleben D, et al. High prevalence of occult left heart disease in scleroderma-pulmonary hypertension. Eur Respir J 2013; 42: 1083-1091.

2 Hachulla E, Gressin V, Guillevin L, et al. Early detection of pulmonary arterial hypertension in systemic sclerosis: a French nationwide prospective multicenter study. Arthritis Rheum 2005; 52: 3792-3800.

3 Mukerjee D, St George D, Coleiro B, et al. Prevalence and outcome in systemic sclerosis associated pulmonary arterial hypertension: application of a registry approach. Ann Rheum Dis 2003; 62: 1088-1093.

4 Quinones MA, Gaasch WH, Alexander JK. Influence of acute changes in preload, afterload, contractile state and heart rate on ejection and isovolumic indices of myocardial contractility in man. Circulation 1976; 53: 293-302.

5 Fujimoto N, Borlaug BA, Lewis GD, et al. Haemodynamic responses to rapid fluid loading: the impact of age, sex and heart failure. Circulation 2013; 127: 55-62.

6 Ling Y, Johnson MK, Kiely DG, et al. Changing demographics, epidemiology, and survival of incident pulmonary arterial hypertension: results from the pulmonary hypertension registry of the United Kingdom and Ireland. Am J Respir Crit Care Med 2012; 186: 790-796.

7 Hurdman J, Condliffe R, Elliot CA, et al. ASPIRE registry: assessing the Spectrum of Pulmonary hypertension Identified at a REferral centre. Eur Respir J 2012; 39: 945-955.

8 Hatano S, Strasser T. Primary Pulmonary Hypertension: Report on a WHO Meeting, Geneva 15-17 October 1973. Geneva, World Health Organization, 1975.

9 Galiè N, Hoeper MM, Humbert M, et al. Guidelines for the diagnosis and treatment of pulmonary hypertension: the Task Force for the Diagnosis and Treatment of Pulmonary Hypertension of the European Society of Cardiology (ESC) and the European Respiratory Society (ERS), endorsed by the International Society of Heart and Lung Transplantation (ISHLT). Eur Heart J 2009; 30: 2493-2537.

10 Leung CC, Moondra V, Catherwood E, et al. Prevalence and risk factors of pulmonary hypertension in patients with elevated pulmonary venous pressure and preserved ejection fraction. Am J Cardiol 2010; 106: 284-286.

11 Escribano-Subias P, Blanco I, López-Meseguer M, et al. Survival in pulmonary hypertension in Spain: insights from the Spanish registry. Eur Respir J 2012; 40: 596-603.

12 Hachulla AL, Launay D, Gaxotte V, et al. Cardiac magnetic resonance imaging in systemic sclerosis: a crosssectional observational study of 52 patients. Ann Rheum Dis 2009; 68: 1878-1884. 
13 Follansbee WP, Miller TR, Curtiss EI, et al. A controlled clinicopathologic study of myocardial fibrosis in systemic sclerosis (scleroderma). J Rheumatol 1990; 17: 656-662.

14 Luchsinger PC, Seipp HW Jr, Patel DJ. Relationship of pulmonary artery-wedge pressure to left atrial pressure in man. Circ Res 1962; 11: 315-318.

15 Halpern SD, Taichman DB. Misclassification of pulmonary hypertension due to reliance on pulmonary capillary wedge pressure rather than left ventricular end-diastolic pressure. Chest 2009; 136: 37-43.

16 Gibson DN, Di Biase L, Mohanty P, et al. Stiff left atrial syndrome after catheter ablation for atrial fibrillation: clinical characterization, prevalence, and predictors. Heart Rhythm 2011; 8: 1364-1371.

17 Verel D, Stentiford N. Comparison of left atrial pressure and wedge pulmonary capillary pressure: pressure gradients between left atrium and left ventricle. Br Heart J 1970; 32: 99-103.

18 Frost AE, Farber HW, Barst RJ, et al. Demographics and outcomes of patients diagnosed with pulmonary hypertension with pulmonary capillary wedge pressures 16 to $18 \mathrm{mmHg}$ : insights from the REVEAL registry. Chest 2013; 143: 185-195.

19 Naeije R, Vachiery JL, Yerly P, et al. The transpulmonary pressure gradient for the diagnosis of pulmonary vascular disease. Eur Respir J 2013; 41: 217-223.

20 Tatebe S, Fukumoto Y, Sugimura K, et al. Clinical significance of reactive post-capillary pulmonary hypertension in patients with left heart disease. Circ J 2012; 76: 1235-1244. 